\title{
Knowledge of mothers about use of fissure sealant therapy and professional fluoride therapy among children in Saudi Arabia
}

\author{
M Zakirulla*, Malaz M Mustafa, KS Ravi, Yomna S Alwabel, Manal A Aldayel, \\ Wafa'a S Alshareef \\ Department of Pediatric Dentistry \& Orthodontic Sciences, College of Dentistry, King Khalid University, Abha, Kingdom of Saudi
} Arabia

*For correspondence: Email: drzak786@gmail.com; Tel: 00966-17248028

Sent for review: 4 April 2019

Revised accepted: 19 September 2019

\begin{abstract}
Purpose: To evaluate mothers' knowledge of the use of fissure sealant (FS) and topical fluoride (TF) therapy among children aged between 7 to 12 years in Saudi Arabia.

Methods: In this cross-sectional study, participants $(n=350)$ were selected based on simple random sampling method from the mothers' of children aged from 7 to 12 years old, attending outpatient pediatric dental clinics in College of Dentistry King Khalid University, Abha, Saudi Arabia.

Results: The age group of mothers included are as follows: $31.7 \%$ in 20 - 30 years age group, $53.1 \%$ in 31 - 40 years age range, and $15.1 \%$ in 41 - 50 years. On FS therapy benefits in the prevention of caries in children, $22 \%$ responded that it was beneficial. When participants were asked regarding FS wearing out easily after application on the tooth, $8 \%$ agreed while $13.4 \%$ disagreed. A majority of mothers $(40.9 \%)$ agreed that TF therapy prevents caries, while $47.7 \%$ stated that they brush twice daily with fluoride toothpaste. The mothers that disagreed that fluoride gel is recommended only for children, not for adults were $32.9 \%$. When the mothers were asked about the benefit of fluoride if its cost is taken into consideration, $46.6 \%$ disagreed that fluoride gel was worth its cost, while $22.3 \%$ took the opposite view.

Conclusion: Positive knowledge of FS and TF therapy have been observed among mothers. However, mothers demonstrated greater positive knowledge of TF therapy than FS therapy.
\end{abstract}

Keywords: Mother's knowledge, Fissure sealant therapy, Topical fluoride therapy, Oral health, Dental caries

This is an Open Access article that uses a fund-ing model which does not charge readers or their institutions for access and distributed under the terms of the Creative Commons Attribution License (http://creativecommons.org/licenses/by/4.0) and the Budapest Open Access Initiative (http://www.budapestopenaccessinitiative.org/read), which permit unrestricted use, distribution, and reproduction in any medium, provided the original work is properly credited.

Tropical Journal of Pharmaceutical Research is indexed by Science Citation Index (SciSearch), Scopus, International Pharmaceutical Abstract, Chemical Abstracts, Embase, Index Copernicus, EBSCO, African Index Medicus, JournalSeek, Journal Citation Reports/Science Edition, Directory of Open Access Journals (DOAJ), African Journal Online, Bioline International, Open-J-Gate and Pharmacy Abstracts

\section{INTRODUCTION}

Dental caries is an infectious disease affecting mostly among children but can be prevented at early stages [1]. Early childhood caries leads to pain, lack of growth, loss of confidence and mental health problems. Several studies conducted in Saudi Arabia related to prevalence of dental caries among various age groups and places. A study conducted among 6 to 13-year old children revealed $85.4 \%$ prevalence of dental caries in Asir region [2]. 
Recently, a study was conducted in Abha, Saudi Arabia, reported in an age group of $15-17$ years old school children were having $72.9 \%$ prevalence of dental caries and recommended that there is an emergency need for the approval of preventive oral health programs and take dental treatment to preserve the permanent dentition into advanced age [3]. This statistic shows an urgent need for major interventions to reduce the burden of dental caries through prevention [4]. More than $50 \%$ of decay occur in under 20 year old pediatric patients in the dental pit and fissures thereby necessitates the use of pit and fissure sealants (FS) as another way of prevention.

Pit and fissure sealant application on permanent teeth (first molar) has decreased dental caries from $86 \%$ in the first year to $78.6 \%$ in the second and.'58.6 \% in the 4th year [5]. Most scientific evidence indicates that TF therapy applied by a Dentist can effectively reduce the incidence of dental caries [6]. Topical application of fluoride by a Dentist four times a year has been reported to result in.' $86 \%$ reduction in the number of dental caries [7]. Despite the use of preventive procedures, percentage of children involving in these services are less [8]. One of the barriers to the utilization of.'preventive dental cares is lack.'of public awareness [9]. Knowledge of mothers about professional preventive dental care is very important to improve the collective consciousness to improve the oral health of children. Parents good oral hygiene practices such as tooth-brushing, awareness of fluoride benefits, good diet and consciousness of good oral health, have important effect on the oral health behavior among children.

The first step to promote the utilization of preventive dental cares is to increase the knowledge and attitudes of parents about.'the importance of such cares as parents play an crucial role in developing.'healthy oral habits in children and have the responsibility of maintaining and improving the child's oral health [10]. However, very few studies have reported the mother's knowledge and attitude of preventive dental procedures. The aim of the current study was to determine the knowledge of mothers towards FS and TF therapy of their children in Abha city, Saudi Arabia.

\section{METHODS}

The present study is a cross-sectional survey. Total 350 participants were selected by simple random sampling method from the mothers' of children aged from 7 to 12 years old, attending outpatient pediatric dental clinics in College of Dentistry King Khalid University, Abha, Saudi Arabia. The study was approved by the ethical approval committee at the College of Dentistry King Khalid University (approval no. SRC/ETH/2017-18/088). Before clinical oral examination of child patient, parent's written informed consent was obtained.

All the participants were requested to complete a comprehensive questionnaire in Arabic (local Language). Each participant given instructions regarding the filling of the questionnaire and made aware of the aims of the study. The questionnaire was designed to evaluate the knowledge, attitudes, and practices of the mother's awareness of FS and TF therapy.

\section{Validity of questionnaire}

To validate and the face validity, it was submitted to expert's review and they will approve the questions (10 questions), and their opinions were recorded for face validity. To validate for content validity of the questionnaire, 10 mothers were tested as convenience sample. Later, mothers were asked to give the feedback on the overall questionnaire clarity in terms of length and language. Mothers were excluded in the participation in the final sample, who were included in pilot study and no modification was required in the questionnaire.

\section{Sample population}

The sample size was calculated as in Eq 1. From the literature survey the expected prevalence is $35 \%$, so for precision, $5.0 \%$ the estimated sample size was 350 .

$n=Z^{2} p(1-p) / d^{2}$

where $\mathrm{n}=$ sample size, $\mathrm{Z}=\mathrm{z}$ statistics for given level of confidence $=1.96$ (for $95 \%$ C.I.), $p=$ expected prevalence $=35.0 \%, d=$ precision $=$ $5.0 \%$.

\section{Inclusion criteria}

- $\quad$ All mothers who have children aged $7-2 y$.

- Residing in the geographical region of Abha region, Aseer District, KSA.

- Any one of the children should have taken treatment for preventive dental procedures, either FS or TF therapy.

\section{Exclusion criteria}

All incomplete responses will be excluded from the study. The questionnaire includes data 
regarding the mother's age, education level and a number of children. Knowledge questions were prepared based on other studies [11-13], and clinical guidelines published by American Dental Association, European Academy of Pediatric Dentistry (APD), and American APD in the field of FS \& TF therapy. The questionnaire consisted of 10 questions and was designed based on 3 point Likert scale $(1=$ agree, $2=$ disagree, and 3 $=$ No idea). The practice section questions are about the experiences of mothers on these preventive treatment.

\section{Statistical analysis}

Both descriptive and analytical statistical measurements were used to describe the main variables by SPSS 18 (IBM Corporation, Armonk, New York, USA) software. Chi-square, ANOVA, and Pearson's correlation coefficient were used to compare the qualitative and quantitative variables. The statistical significance of the coefficients in the statistical analyses was tested at $p<0.05$.

\section{RESULTS}

The face validity of the questionnaire was evaluated. Knowledge questions were all multiple choice and in the form of "Agree", "Disagree" and "No Idea." A score of 1 and 0 was considered for the correct and wrong answers, respectively. The alpha-Cronbach's coefficient was 0.374 and 0.521 , respectively, for the reliability of questions included in knowledge about FS and TF therapy sections, respectively.

Total participants included in the study were 350 , between the age group of 20 to 50 years. The result regarding the percentage distribution of mothers according to age, educational level and a number of children were summarized (Table 1 ). $31.7 \%$ were 20 - 30 years age group, $53.1 \%$ were 31 - 40 years of age, and $15.1 \%$ were 41 50 years of the age group of mothers. The result regarding the frequency of responses to questions related to preventive dental procedures in children, ie., FS and TF therapy among mothers were summarized (Table 2, Figures 1 \& 2). When mothers were asked regarding whether FS therapy makes child fear, $12.9 \%$ were agreed, and 15.1 disagreed. Majority of the participants, ie, $22 \%$ agreed that FS therapy benefits in the prevention of caries in children. When participants were asked regarding FS wear out easily after application on the tooth, $8 \%$ were agreed, and $13.4 \%$ disagreed. Majority of mothers, $40.9 \%$ agreed that fluoride gel material would prevent caries, while $47.7 \%$ agreed to brush twice daily with fluoride toothpaste. Mothers disagreed that fluoride gel recommends only for children, not for adults were $32.9 \%$. When the mother was asked regarding the benefit of fluoride compared to its costs, $46.6 \%$ disagreed to benefits of fluoride worth its costs, while $22.3 \%$ only agreed.

Table 3 shows frequency ( $N$, \%) of mother's knowledge who answered the questions correctly out of 350 samples. Comparison of mean difference in knowledge scores at various age groups (Figure 3) and educational level of mothers (Figure 4) for FS and TF therapy. The mean knowledge score of both preventive procedures (FS and TF) was found to be more in 41-50 years of age group followed by $31-40$ years and $20-30$ years of the age group of mothers. Table 4, shows Pearson's correlation of scores of mothers' knowledge and a number of children showed a week positive correlation between these two variables $(p>0.05)$, the correlation coefficient for FS therapy (0.088) and for TF therapy of $(0.116)$.

Table 1: Distribution of study subjects according to age, education level and the number of children

\begin{tabular}{lcc}
\hline Age & N & $\%$ \\
\hline 20-30 years & 111 & 31.7 \\
31-40 years & 186 & 53.1 \\
Education level & 53 & 15.1 \\
Academic & 80 & 22.9 \\
Diploma & 171 & 48.9 \\
High school & 77 & 22.0 \\
Illiterate & 22 & 6.3 \\
No. of Children & & \\
1 & 58 & 16.6 \\
2 & 61 & 17.4 \\
3 & 71 & 20.3 \\
4 & 77 & 22.0 \\
5 & 35 & 10.0 \\
6 & 18 & 5.1 \\
7 & 10 & 2.9 \\
8 & 12 & 3.4 \\
9 & 5 & 1.4 \\
10 & 2 & 0.6 \\
11 & 1 & 0.3 \\
\hline
\end{tabular}


Table 2: Frequency of responses to questions by mothers related to the two methods of preventive procedures among their children.

\begin{tabular}{|c|c|c|c|c|c|c|c|}
\hline Questions & Choiles & Agret & Disagré & No Idea & Total & N.A. & Total \\
\hline \multicolumn{8}{|c|}{ 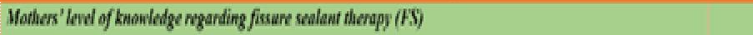 } \\
\hline 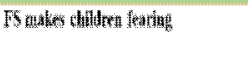 & $\begin{array}{c}x \\
8\end{array}$ & 等 & $\begin{array}{l}53 \\
3(1)\end{array}$ & 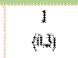 & ty & $\begin{array}{l}288 \\
(71.5\end{array}$ & 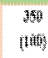 \\
\hline IS beeclis ia presalien of caris & $\begin{array}{c}\mathrm{K} \\
(5)\end{array}$ & $\begin{array}{c}77 \\
(219)\end{array}$ & $\begin{array}{l}\text { is } \\
(14)\end{array}$ & (a) & ini. & $\begin{array}{c}\$ 41 \\
{[1.7]}\end{array}$ & $\begin{array}{l}\text { Bitio } \\
\text { (10ii) }\end{array}$ \\
\hline 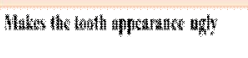 & w & 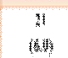 & 稌 & 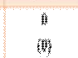 & w & $\begin{array}{l}n \\
n+1\end{array}$ & 被 \\
\hline F wear out eastly, & $\begin{array}{c}\mathrm{N} \\
\text { (\$) }\end{array}$ & $\begin{array}{l}\text { is } \\
\text { (sii) }\end{array}$ & $\begin{array}{c}47 \\
\text { (i1.4) }\end{array}$ & $\begin{array}{l}24 \\
(69)\end{array}$ & (25.) & $\begin{array}{l}39 \\
\text { (11.7) }\end{array}$ & (30i) \\
\hline 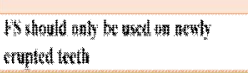 & $\begin{array}{c}3 \\
3\end{array}$ &  & (1) & 23 & 数4 & wit & 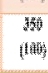 \\
\hline \multicolumn{8}{|c|}{ 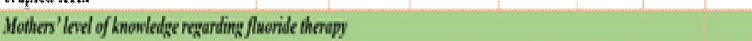 } \\
\hline 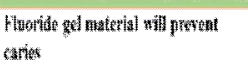 & ?to & 辣 & 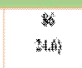 & 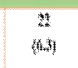 &  & 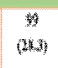 & 裸 \\
\hline Fluorids pal muks childran vomiling & $\begin{array}{c}\mathrm{X} \\
(6)\end{array}$ & $\begin{array}{l}\text { (3) } \\
\text { (2Mi) }\end{array}$ & $\begin{array}{l}198 \\
(H \mathrm{H})\end{array}$ & (2i) & $\begin{array}{l}451 \\
4117)\end{array}$ & $\begin{array}{c}W \\
\text { (a.j) }\end{array}$ & $\begin{array}{l}350 \\
\text { (10ii) }\end{array}$ \\
\hline 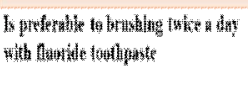 & 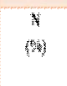 & 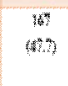 & 韾) & (") & wh & w & 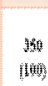 \\
\hline $\begin{array}{l}\text { Fluoride ged revomenceded only for } \\
\text { childrea ool for adults. }\end{array}$ & $\begin{array}{c}\mathrm{N} \\
\text { (5i) }\end{array}$ &  & $\begin{array}{l}118 \\
(229)\end{array}$ & $\begin{array}{l}189.9 \\
(109)\end{array}$ & $\begin{array}{l}195 \\
\text { (15.7) }\end{array}$ & $\begin{array}{c}\text { W } \\
\text { (2.S) }\end{array}$ & $\begin{array}{l}30 \\
(100)\end{array}$ \\
\hline 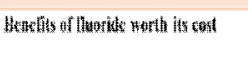 & 篓 & $\frac{7}{4}$ & 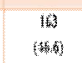 & 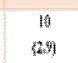 & H & $\begin{array}{c}\text { w } \\
\ldots\end{array}$ & 政 \\
\hline
\end{tabular}

Table 3: Mothers who answered the questions correctly out of 350

\begin{tabular}{|c|c|c|}
\hline $\begin{array}{l}\text { Mothers' level of knowledge } \\
\text { regarding fissure sealant therapy (FS) }\end{array}$ & $\mathbf{N}$ & $\%$ \\
\hline FS makes children fearing & 53 & 15.1 \\
\hline FS benefits in prevention of caries & 77 & 22.0 \\
\hline Makes the tooth appearance ugly & 78 & 22.3 \\
\hline FS wear out easily. & 47 & 13.4 \\
\hline $\begin{array}{l}\text { FS should only be used on newly } \\
\text { erupted teeth }\end{array}$ & 67 & 19.1 \\
\hline \multicolumn{3}{|l|}{$\begin{array}{l}\text { Mothers' level of knowledge } \\
\text { regarding fluoride therapy }\end{array}$} \\
\hline Fluoride gel material will prevent caries & 143 & 40.9 \\
\hline Fluoride gel makes children vomiting & 155 & 44.3 \\
\hline $\begin{array}{l}\text { Is preferable to brushing twice a day } \\
\text { with fluoride toothpaste }\end{array}$ & 167 & 47.7 \\
\hline $\begin{array}{l}\text { Fluoride gel recommended only for } \\
\text { children not for adults. }\end{array}$ & 115 & 32.9 \\
\hline Benefits of fluoride worth its cost & 78 & 22.3 \\
\hline
\end{tabular}

Table 4: Relationship of number of children and knowledge scores of fissure sealant therapy (KSFST) and fluoride therapy (KSFT)

\begin{tabular}{lcc}
\hline Variable & KSFST & KSFT \\
\hline Pearson correlation & 0.088 & 0.116 \\
$P$-value & 0.387 & 0.067 \\
$\mathrm{~N}$ & 99 & 251 \\
\hline
\end{tabular}

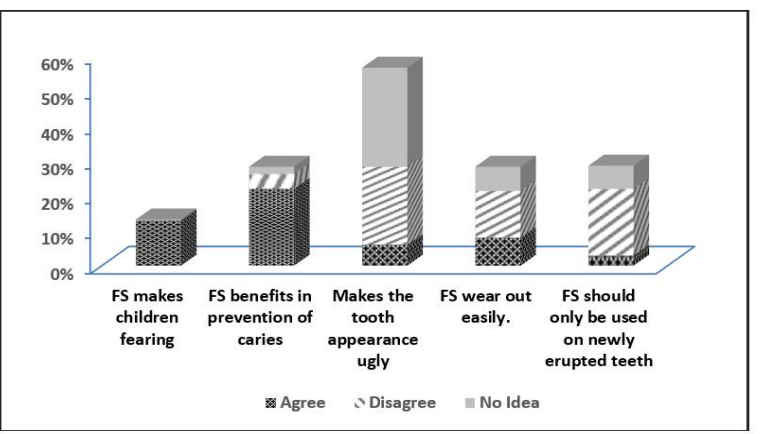

Figure 1: Knowledge of mothers regarding fissure sealant (FS) therapy



Figure 2: Knowledge of mothers about topical fluoride therapy



Figure 3: Various age groups of mothers vis-a-vis mean differences in knowledge scores of fissure sealant therapy (KSFST) and fluoride therapy (KSFT)

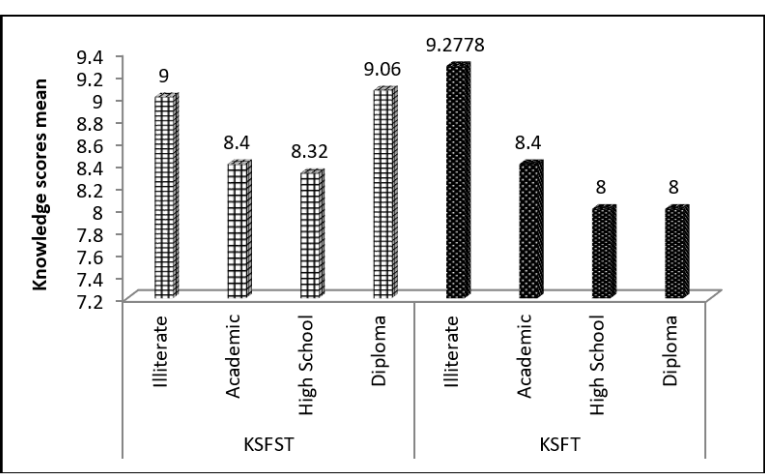

Figure 4: Education level of mothers vis-a-vis mean differences in knowledge scores of fissure sealant therapy (KSFST) and fluoride therapy (KSFT) 


\section{DISCUSSION}

The present study aimed to evaluate maternal awareness of professionally applied preventive treatments. Mothers who have children in the age group of $7-12$ years and who have undergone dental treatment or a preventive dental procedure, e.g., fissure sealant (FS) therapy or topical fluoride (TF) therapy, were interviewed in this study. FS therapy is considered a potent protective procedure for caries in pediatric patients. Both the American Dental Association (ADA) and the American Academy of Pediatric Dentistry (AAPD) recommend the application of FS on deciduous andlor permanent teeth whenever a child is deemed to be at risk of developing dental caries [14]. One study revealed that only $57 \%$ of the parents or legal guardians were conscious of the importance of FS, and less than half of the parents were aware of its caries-preventive properties [15].

A large number of the mothers who were addressed acknowledged the importance of preventive dental procedures and their role in preventing dental caries in children. This information was promising, considering that dental caries can have an impact on the child's overall growth and development. The sequelae of dental caries may lead to substantial pain, serious infections, and lowering of the oral-health quality of life of the children [16]. Most of the respondents in the current study were educated mothers. The maternal educational level is suggested to play a crucial role in the oral health of the offspring, and mothers with a higher education had better knowledge of oral health and importance of preventive dental measures. This observation was in accordance with the results of a study conducted by Nakhjavani [17], which demonstrated that Iranian mothers with a university degree had superior awareness regarding fluoride therapy and fissure sealant procedure. Another valid example of this assumption may be drawn from a study conducted in Saudi Arabia, which claimed that knowledge was influenced by only age, gender, and level of parental education, but was strongly linked to the economic status of the family [18].

Most mothers who participated in the study acknowledged that twice daily brushing using a toothpaste containing fluoride would aid in maintaining a caries-free status with regard to their children's teeth. A similar study, reported in Makkah Al-Mukarrama, Saudi Arabia, found that $90.1 \%$ of mothers were aware of the cariespreventive properties of fluoridated toothpaste [19]. Brushing with fluoridated toothpaste in children is encouraged owing to the sub-optimal fluoride concentration in many parts of Saudi Arabia [20]. Optimal, exposure to fluoride soon after the, eruption of primary teeth is of prime importance for all youngsters [13]. Fluoride has proved to be both harmless and efficacious in preventing and controlling tooth decay. Very few mothers among the participants believed that "FS therapy should be applied exclusively on recently-erupted teeth."

Another important indicator of a parent's knowledge of preventive dental procedures is family size. The relationship between the mothers' knowledge and the number of children exhibited a weak positive correlation, and when compared to the findings of another study conducted by Blumer [21], it showed higher acceptability and contentment with TF products in families having more children. This result was promising because it demonstrated a change in old concepts and an appreciation of the merits of TF in the prevention of dental caries [21]. Increased parental self-awareness towards preventive oral health routines, combined with regular visits to the dentist, was associated with greater acceptance of the application of TF to the teeth of their offspring.

In our study, the majority of mothers (46.6\%), disagreed with the statement that "Benefits of fluoride is worth its costs." This result was similar to that of another study conducted by Albert et al., who claimed that $55.7 \%$ of parents were refusing the FS therapy recommended by American dentists, mostly due to high expenses [22]. Similarly, a study conducted in Iran by Tahani [23] showed that $20 \%$ of parents reported the high cost of treatment as a barrier for implementing preventive dental treatment. Currently, if a strategic plan is adopted by insurance companies to cover the cost of this effective treatment, it will greatly encourage the parents to comply [24]. A majority of mothers did not agree with the view that FS would wear off easily after application in children. This finding is in conflict with the results of a study carried out in India to evaluate the knowledge, value, opinion, and practice concerning the application of FS among private dental practitioners. The study revealed that $62.8 \%$ of dentists working in private dental clinics apply FS infrequently as a preventive dental procedure because of their understanding of its rapid and easy wearing properties [25]. They also reported that the majority of participants $(85.3 \%)$ believed that the optimal protection against decay would be achieved when FS therapy was combined with TF application. Concurrent use of FS and TF was more efficient against caries attack. Application 
of fluoride concomitantly with FS, or its application to the tooth surface before FS therapy, might augment caries resistance while maintaining the properties of the sealant material [26].

\section{Limitations of the study}

The current study gathered information on maternal knowledge regarding preventive dental procedures. Although the mothers' answers were mostly appropriate, it is evident that improvement of knowledge and attitude is needed in several important areas. A limitation of this study is that the research outcomes cannot be generalized.

\section{CONCLUSION}

Carious lesions and periodontal problems are among the most prevalent diseases worldwide, but they can be prevented by increasing maternal awareness of preventive measures in oral health care (such as FS and TF therapies). Nevertheless, the current findings offer insight into overall parental practice, knowledge, and acceptance of preventive dental procedures for children. This study provides valuable information that may be applied to promote oral health. However, the adoption of healthy and preventive oral behaviors does not necessarily result from oral health education; additional influences such as socioeconomic status also play a key role.

\section{DECLARATIONS}

\section{Acknowledgement}

The authors thanks College of Dentistry King Khalid University, Abha, KSA for providing the facilities used to carry out this study.

\section{Conflict of interest}

The authors declare no conflict of interest. No funding was received to conduct the study.

\section{Contribution of authors}

We declare that this work was done by the authors named in this article and all liabilities pertaining to claims relating to the content of this article will be borne by the authors.

\section{Open Access}

This is an Open Access article that uses a funding model which does not charge readers or their institutions for access and distributed under the terms of the Creative Commons Attribution License (http://creativecommons.org/licenses/by/ 4.0) and the Budapest Open Access Initiative (http://www.budapestopenaccessinitiative.org/rea d), which permit unrestricted use, distribution, and reproduction in any medium, provided the original work is properly credited.

\section{REFERENCES}

1. Khan H, Rehman K, Rasool G. Awareness of parents about dental disease and their prevention in children. Pak Oral Dent J 2009; 29: 93298.

2. Abolfotouh MA, Hassan $K H$, Khattab MS, Youssef RM, Sadek A, El-Sebaiei M. Dental caries: experience in relation to wasting and stunted growth among schoolboys in Abha, Saudi Arabia. Ann Saudi Med 2000; 20(5-6): 360-363.

3. Alshahrani I, Tikare S, Meer Z, Mustafa A, Abdulwahab $M$, Sadatullah $S$. Prevalence of dental caries among male students aged 15-17 years in Southern Asir, Saudi Arabia. Saudi Dent J 2018; 30(3): 214-218. doi: 10.1016/j.sdentj.2018.03.003. Epub 2018 Apr 3.

4. Yekaninejad MS, Eshraghian MR, Nourijelyani $K$, Mohammad K, Foroushani AR, Zayeri F, Pakpour $A H$, Moscowchi A, Tarashi M. Effect of a school?based oral health?education program on Iranian children: Results from a group randomized trial. Eur J Oral Sci 2012; 120: 429 ?437.

5. Beauchamp J, Caufield PW, Crall JJ, Donly K, Feigal R, Gooch B, Ismail A, Kohn W, Siegal M, Simonsen $R$. Evidence?based clinical recommendations for the use of pit?and?fissure sealants: $A$ report of the American Dental Association Council on Scientific Affairs. J Am Dent Assoc 2008; 139: 2572268.

6. Merghache $D$, Bellout $B$, Merghache $S$, Boucherit?Atmani Z. Fluoride levels in commercial dentifrices and drinking water in Algeria. Odontostomatol Trop 2011; 34: 20ख28.

7. Mc Donald RE, Avery DR, Stookey GK. Dental caries in the child and adolescent. In: Mc Donald RE, Avery DR, editors. Dentistry for the Child and Adolescent. 7th ed. St. Louis: Mosby; 2000. p. 209?246.

8. Bhuridej $P$, Damiano $P C$, Kuthy RA, Flach $S D$, Kanellis MJ, Heller KE, Dawson DV. Natural history of treatment outcomes of permanent first molars: A study of sealant effectiveness. J Am Dent Assoc 2005; 136: 126501272.

9. Centers for Disease Control and Prevention. Oral Health: Preventing Cavities, Gum Disease, and Tooth Loss; 2007. Available from: http://www.cdc.gov/nccdphp/publication/aag/oh.htm. [Last accessed on 2017 Oct 08].

10. Gill DS, Lee RT, Tredwin CJ. Treatment planning for the loss of first permanent molars. Dent Update 2001; 28 :

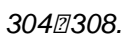

11. Al-Hammadi AA, Al-Rabai NA, Togoo RA, Zakirulla M, Alshahrani I, Alshahrani A. Knowledge, attitude, and behavior related to use of miswak (Chewing Stick): $A$

Trop J Pharm Res, October 2019; 18(10):2194 
cross-sectional study from aseer region, Saudi Arabia. Contemp Clin Dent 2018; 9: S64-S68

12. Marinho VC, Worthington HV, Walsh T, Clarkson JE. Fluoride varnishes for preventing dental caries in children and adolescents. Cochrane Database Syst Rev 2013; 11(7): CD002279.

13. American Academy of Pediatric Dentistry. Guideline on fluoride therapy. Pediatr Dent 2013; 35: E1650168.

14. Crall JJ, Donly KJ. Dental sealants guidelines development: 2002-2014. Pediatr Dent 2015; 37(2): 111-115.

15. Mafeni JO, Messer LB. Parental knowledge and attitudes towards pit and fissure sealants. Aust Dent J 1994; 39(3): 172-180.

16. American Academy of Pediatric Dentistry. Guideline on Infant Oral Health Care. Reference Manual 2012 -2013. Pediatr Dent 2013; 34: 132-136.

17. Nakhjavani BY, Forutan S, Baradaran NF. Mothers knowledge about fluoride therapy and fissure sealants. $J$ Oral Health Oral Epidemiol 2013; 2(1): 1-5.

18. AL-Shalan TA. Saudi parents knowledge of and attitude toward the prevention of dental caries. Saudi Dent $J$ 2003; 15(1): 27-32.

19. Al-Zahrani AM, Al-Mushayt AS, Otaibi MF, Wyne AH. Knowledge and attitude of Saudi mothers towards their preschool children's oral health. Pak J Med Sci 2014; 30(4): 720-724. http://dx.doi.org/10.12669/pjms.304.5069.
20. AIDosari AM, Akpata ES, Khan N, Wyne AH. Fluoride levels in drinking water in the central province of Saudi Arabia. Annals Saudi Med 2003; 23: 37-40.

21. Blumer S, Ratson T, Peretz B, Dagon N. Parents' Attitude towards the Use of Fluorides and Fissure Sealants and its Effect on their Children's Oral Health. J Clin Pediatr Dent 2018; 42(1): 6-10.

22. Albert DA, Ahluwalia KP, Schooley E, Sadowsky $D$. "Socioeconomic factors affecting sealant placement by dentists in a national insurance plan," in Proceedings of the 128th Annual Meeting of American Public Health Association (APHA '00), Abstract no. 14570, 2000: 1216.

23. Tahani B, Yadegarfar G, Ahmadi A. Knowledge, attitude, and practice of parents of 7-12-year-old children regarding fissure sealant therapy and professional fluoride therapy. J Edu Health Promot 2017; 6: 106.

24. Al Agili DE, Niazy HA, Pass MA. Prevalence and socioeconomic determinants of dental sealant use among schoolchildren in Saudi Arabia. East Mediterr



25. Asawa K, Gupta VV, Tak M, Nagarajappa R, Chaturvedi $P$, Bapat S, Mishra P, Roy SS. Dental Sealants: Knowledge, Value, Opinion, and Practice among Dental Professionals of Bathinda City, India. Adv Prev Med 2014; 2014: 469738.

26. Selwitz RH, Nowjack-Raymer R, Driscoll WS, Li SH. Evaluation after 4 years of the combined use of fluoride. Pediatr Dent 2002; 24: 25. 